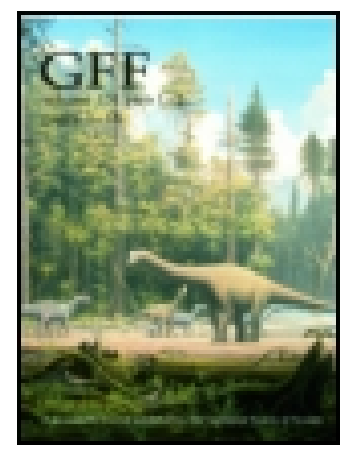

Geologiska Föreningen i Stockholm Förhandlingar

\title{
Om Siljanstraktens sandstenar
}

\section{Stolpe}

To cite this article: M. Stolpe (1872) Om Siljanstraktens sandstenar, Geologiska Föreningen i Stockholm Förhandlingar, 1:2, 17-26, DOI: 10.1080/11035897209443799

To link to this article: http://dx.doi.org/10.1080/11035897209443799

$$
\text { 曲 Published online: } 06 \text { Jan } 2010 .
$$

Submit your article to this journal ๘

Џll Article views: 10

Q View related articles $\square$ 


\title{
GE0LOGISKA FÖRENINGENS
}

\author{
I STOCKHOLM \\ FÖRHANDLINGAR.
}

BAND I.

N:o 2.

Innehãll: Mötet d. 7 Februari 1S72, - StoLPE, M. Om Siljanstraktens sandstenar. NoRDexströs, O. G. Bidrag till kännefomen or Dalkarlsbergs.malmfilt - Fynd af ctt kiluriskt lager 1 bohusläns slärgård. - Törxeвonх, A. E. Om förekomsten af serpentin 1 Jemtlana. - Gcacelcs, 0 . Qvarts och bergkristaller i kornig kalksten.

Motet d. 7 Februari 1872.

IIr NoRDENSTRōM - meddelade några geognostiska upplys-

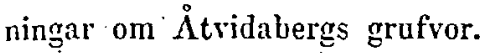

Ir . Linnarsson redogjorde för sina iakttagelser $i$ afseende pá Jemtlands siluriska bildningar.

Ifr Cleve omnämnde fyndet af ett siluriskt lager i Bohusläns skïrgård, från hvilket äfven stuffer förevisades oçh öfverlemnades till Geologiska Byråns samlingar.

IIr BōRTzELL redogjorde för några nya litográfiska tryckningsmetoder och deras anvïndbarhet för geologiska kartor.

Ir GUMæLiUs omnämnde förekomsten af kristalliserad qqarts i kornig kalksten. från trakten af Nंora.

Ir TórneboHur meddelade några iakttagelser om serpentin i Jemtland.

Stolpe, M. Om Siljanstraktens sandstenar. Tafl. 2.

I "Öfversigt af K. Vetenskapsakademiens Förhandlingar" för år 1871 hafva meddelats iakttagelser rörande silurformationen i Siljanstrakten af IIrr TöRNQvist och LiNNaRsson. Såsom tillägg till dessa torde nedanstående betraktas.

Under sommaren 1869 företog nu mera afl. prof. A. ERDMANN en resa till Dalarne och var jag honom då füljaktig. Bland 
annat som under resan kom på tal var Dalarnes ljusa, lösa sandsten, på några ställen använd till slipsten, och uttryckte härvid Prof. Erduan sin tvekan angående riktigheten af den allmänt antagna åsigten, att denna sandsten underlagrade de siluriska bildningarne. ' I planen för vår resa ingick likväl icke då någon undersökning för utredande af denna fråga. Följande år uppdrog̣s åt mig att ånyo göra ett besök i Dalarne för att dels nürmare studera silurlagren, dels undersöka, så mycket som kunde medhinnas, de ännu föga künda skogstrakterna mellan Ore elf och Siljan. Äfven under sistlidne sommar 1871 erhöll jag tillfïlle att under några dagars resa komplettera mina fürra iakttagelser, och skall jag här nedan meddela dessa, samt de slutsatser, till hvilka jag kommit, för så vidt de röra sandstenarnes förhållande till öfriga aflagringar.

Härvid har jag användt de benämningar Hr TỏnNQvtsr gifvit de olika lagren, med undantag deraf, att jag gifvit namnet Slipsandsten åt den allmännast förekommande lösa sandstenen, som till färgen vexlar mellan hvit, gul och svagt röd, med och utan flïckar, med och utan små inneslutningar af lera, samt att jag delat cementkalken i Styggforskalk, den kalksten, som uppträder jemte sferoidskiffern, och Gulleråskalk, den kalksten, som atföljer trinucleusshiffern. Tónnevists och Linnarssons benümningar har jag på följande sätt sökt sammanställa.

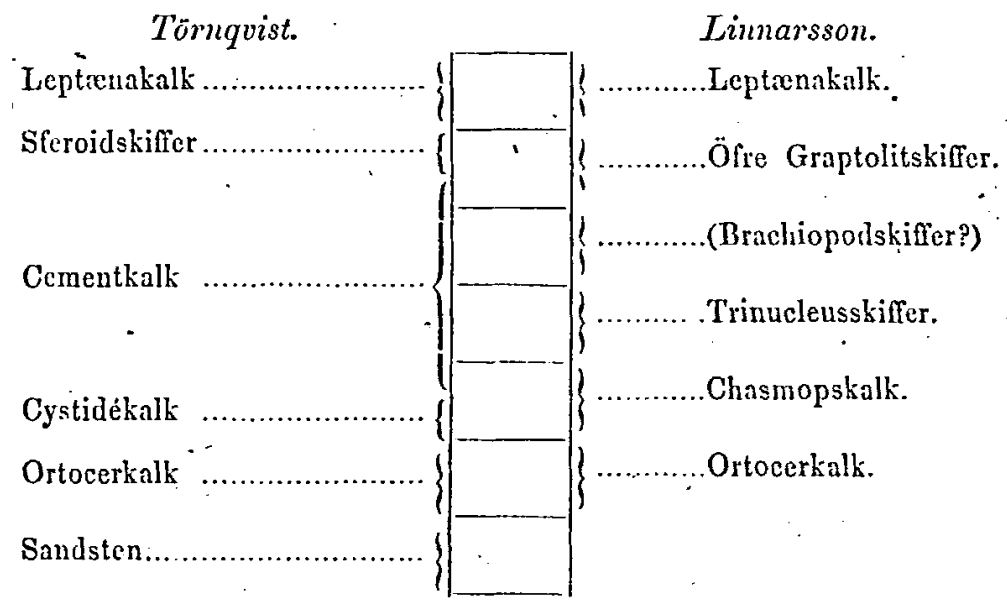


Om vi först taga förhållandena på Sollerön i betraktande, ${ }^{*}$ ) se vi att graniten, som skjuter upp $i$ midten af ön, åt nordvest :ir underlag för ortocerkalk och cystidékalk. Längre àt samma håll träffas sandsten. Mellan kalkstenen och sandstenen är en liten sänka, ur hvilken ej långt från kyrkan skiffer uppgrïfts och användts för tegeltillvẹrkning - enligt TönNQvist sferoidskiffer. . Nagot nordligare har jag i samma lilla dalgång funnit, en mängd bitar af Styggforskalk. Profil N:o 1, tafl. 2 áskådliggör närmare nümda förhållande. Kalklagren luta endast omkring $15^{\circ}-20^{\circ}$ àt N.V., sandstenen har ännu mindre stupningsvinkel.

Öster om Orsasjön, nüra grünsen mellan Mora och Orsa socknar, sýnes ortocer- och cystidékalk i sluttningen från höjdẹn ner mot sjön. Ãfven cementkalk har TöRNQvisT råkat i samma sluttning, och stycken af swart skiffer har jag funnit vid gräfning ännu närmare sjön. Vid stranden, samt på sjöbottnen utmed stranden vid Vattnäs, ligger slipsandsten i sidan mängd, att man utan fara för misstag kan påstå, att han här en gång funnits i fast klyft. Pỉ en profilteckning (se prof. 2) skulle således sandstenen $f_{i i}$ sin plats efter de nämda lagren och följaktligen, on man antager'hos honom samma restliga stupning, vara yngre.

Närmare Orsa kyrka ser man samma lagerföljd. Vid Enån är nemligen ortocerkalk, cystidékalk, cementkalk, ${ }^{* *}$ ) (förmodligen Gulleri̊skalk) med inlagrad Trinucleusskiffer, och strax sydligare, mellan byarne Ilolen och Lunden, ïnnu en länk i kedjan, Styggforskalk med grå graptolitskiffer. Om sandstenen vid Vattnäs tänkes följa stranden hit upp, skulle äfven här de föregående profilerna upprepas.

Fortsütta vi vidare från Orsasjön utmed Ore elf, så finna vi nüra Fredshammar de bekanta slipstensbrotten vid Kallmora

*) Se bifogade karta, Tafl. 2. Till grund för densamma ligga ej allenașt mina cgaa undersōkningar, ntan ock de, som före mig blifvit gjorda of Prof. Erduanx. Kartans tryckning är bekostad frản en af Geologiska Byråns tjenstemän bildad kassa.

") Enligt Töswovist. Iagret rar täckt af sand och grus när jag besöktc platsen. 
m. fl. byar. En profillinje dragen frin detta brott, åt $S$. öfver Kallholen till Ảberga, ait $N$. öfver Ore elf ett stycke öfver vestra stranden af Emån, skulle genomsküra följande lager: vid Åberga ortocer- och cystidékalk, vid, Kallholen Styggforskalk och svart graptolitskiffer (sferoidskiffer) samt pii höjden leptæenakalk, och närmast Ore elf slipsandsten. Norr om elfven skär hon öfver samma sandsten och omkring 3000 fot nordligare grả ortocereller möjligen cystidékalk, hrilande på en röd, hảrd sandsten, helt olik slipsandstenen. Bidde fri̊n $\mathrm{N}$. och $\mathrm{S}$. luta lagren ner mot elfven. Slipstensbrotten visa visserligen på skilda stïllen stupning it olika hill, men i stort torde man kuma antaga lutningen mot elfven. Med stöd häraf' och' af TönNevists fynd af skiffer, "helt sïkert sferoidskiffer", uppgräfd ur marken strax S. om stenbrotten, blir den ả vidfogade karta tecknade profilen Noo 3, ehuru icke afgiordt riktig, ätminstone ganskiz sannolik.

Om vi nu flytta vïra undersökningar till Rättvik, se vi öster om V'lkarbyn, i närheten af Nittsjö by, silurbäddar af olika slàg blottade. Nära Amtjürn, vid vestra sidan af Amtjïmsbücken - si kallas det vattendrag; som frîn $\mathrm{N}$. faller ut $\mathrm{i}$ Nittsjöbäcken - ligger ett stort kalkbrott, rid den ïstra sidan af samma biick ett icke mindre stort lertag. Kalkstenen är leptænakalk, leran är sferoidskiffer. Törnxovist har dessutom funnit- cementkalk; förmodligen Styggforskalk, närmast under skifferl. Följa vi bäcken utför, sấ se vi, sâ fort skiffern upphört, en in̈̈ngd större och mindre. block af' slipsandsten strödda ända fram till Nittsjübäcken, och till sảdan myckenhet, att man icke kan tvifla om, att ju här sandstenen måste funnits $i$ fast klyft. Vid griifning med spett och spade triiffide jag ett block hela två fot tjockt. Söder om vestligaste gảrdarne i Nittsjo by är en liten gata, som går åt ö. uppför höjdsluttningen. I denna gata uppsticka flera silurlager, rätt mycket resta, kanske t. o. m. lodrätt stånde. Längst ner liknar kalken Styggforskalk, vidare kommer, uppåt räknadt, en gri finkornig kalk $i$ tunna skifvor, i hvilken förekomma rïtt många små, för blottạ 
jgat nïstan osynliga, trinda korn af mattfïgad kvarts (IINNanssons brachiopodskiffer?), derpå vexlande röd skiffer och röd kalk samt högre upp grá kalk. P’å annat ställe, niggot sydligare, ar ett kalkbrott pai röd ortocerkalk närmast graniten, som uppe på höjden gair i dagen. Någon annan plats för slipsandstenen än $\mathrm{i}$ och vid sjelfva bäckfiran låter svărligen tänka sig.

Vid Born, öster om nỵa vägen mellan Rättvik och Boda, ir slipsandsten blottad i bygatan vester om byn och brytes äfren härstiides. Stupningen är svag ait Ö. under leptænakalken, som pai andra sidan vägen ligger $i$ dagen.

Slutligen vid Styggforsen och en strïcḱa derifrán neråt ån se vi slipsandstenen $\mathrm{i}$ kontakt med Styggforskalken, den ene liggande ömsom öfver, ömsom under den andre. Efter ett afbrott uppträ̈ler samma sandsten fürst utmed an vid Ofvanmyra, längre ner vid Vestaná by har han brutits upp i stor mingd i sjelfva liöjdsluttningen rester om in och der har man ock, nágot längre ut frion sluttningen, brutit leptænakalk. Om ingendera af dessa bergarter kan jag dock med full siikerhet säga, att de hiir ïro i fast klyft.* )

Ofvanstiende fakta, sammanstälda och jemförda med hvarandra, torde göra slipsandstenens plats under alla de olika kalkoch skifferlagren mindre sannolik. De utesluta visserligen icke möjligheten af en sådan förklaring, ty rubbningar i lagrens ursprungliga läge kúnna jemte denudationer göra förhållandena si̊ invecklade, att de tillåta olika tolkningar, men de fordra ingenstïdes med nödvändighet några häftiga förskjutningar eller kastningar för att kunna rätt förklaras. Eget förefaller det ock, att Dalarnes äldsta kalksten, ortocerkalken, icke pí nágot ställe, mig veterligen, der han ligger nära eller intill grundberget, funnits skild frain detta genom slipsandsten. Jag vill utom redan nämda

*) Fndast $i$ förbigående vill jag frambålla min trekan, on leptrankalkea bör tänkas $\mathrm{i}$ omedelbart sammanhang med de ofriga silurlagren i Dalarne. Att lan öfrerlagrar alla de andra är otvifvelaktigt, men lika visst är icke, att han intagit sin ställning konkordant med dem, åtminstone saknas icke anledningar for ett sådant trifvel. Stor srårighet för en riktig bestämningr häraf är den omstän. digheten; att kalksteaen sällas visar en tydlig skiktbygnad. 
punkter påpeka Vikarbyn, Ôja, Fjecka och Gulleråsen. Vid Öja äro ortocerkalken och graniten skilda genom landsvägen. Den röda, sandstenslika bergart, som fylt niogra fina sprickor i graniten, torde icke vara tillräckligt bevis för att ett sandstenslager finnes närmast graniten, och äfven med detta antagandẻ bevisas det åtminstone icke, att denna sandsten varit den jag här kallat slipsandsten. I Gulleråsen genom hela norra delen af byn, som är utsträckt i $N$. och S., ligger slipsandsten dels nära ytan, dels norr om Byggmüstargården i dagen, der omgifven både it $V$. och $O$. af ortocerkalk, allt stupande omkring $40^{\circ}$

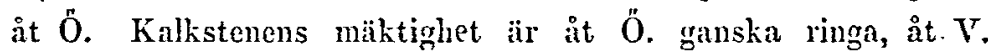
synes den aiter hafva varit riitt betydlig. Ẩnnu på 6-7000 f. afstånd från byn it vester trïffas ortocerkalken uppe på höjden och sluttningarne. En förkastning är här långt ifrån otänkbar, men en denudation nog stark att förstöra den mïktiga ortocerkalken så nära som på några fỉ fot, skulle helt visst icke hafva lemnat oss kvar många spår efter de yngre bïddarne, som dock nu bilda höjdsträckningen genom byn. Mera sannolikt anser jag det vara, att sandstenen $\mathrm{i}$ Gullerảsen ï ett lager $\mathrm{i}$ ortocerkalkens yngsta skikt. Förgäfres har jag vester om byn sökt honom, ehuru ortocerkalken pi många ställen der är $\mathbf{i}$ tydlig kontakt med grundberget, och sandstenen således skulle hafva godt tillfälle att visa sig, om han verkligen hade sin plats mellan kalken och graniten.

Hittils hafva inga försteningar erhållits ur slipsandstenarne, och af blotta utseendet hafva ri ingen tillräcklig ledning för att afgöra deras ílder. Di̊ derjemte hela lagerserien icke på något enda ställe blifvit funnen fullständigt representerad, och dĩ vidare de respektive lagrens mäktighet vanligen är ringa och jordtäckning ofta hindrar att afgöra, om en lïnk $\mathrm{i}$ serien fattas eller endast är gömd, sii ligger ingen orimlighet i den frågan: ăro alla s. k. slipsandstenar frin samma nivä? Jag har nyss framkastat en förmodan, att slipsandstenen i Gulleråsen kan betraktas såsom ett lager $\mathbf{i}$ ortocerkalken, och jag skall $\mathbf{i}$ det följande framlïgga iakttagelser från andra punkter, der en 
trekan om sandstenens förekommande inom skilda grupper kan uppstå.

Vid Blackmyrbäcken, som V. om Osmundsberget utfaller i Bysjön, är slipsandsten $\mathrm{i}$ kontakt med och hvilande på ortocerkalk, som sjelf gränsar närmast till granit.

Vid Osmundsberget går slipsandsten i dagen helt nära berget, men vid borrning nåddes icke sandsten (oafgjordt livilken) förr in vid 386 fot.

I borrbrunnen mellan Vestanå óch Solberga träffades en sandsten först vid 811 fots djup, närmast graniten, under det att slipsandsten ligger $\mathrm{i}$ dagen kort derifrin it $\mathrm{N}$. i samma dalsluttning, och troligen ännu närmare åt $V$. på andra sidan ån.

I Draggi borrbrunn befans sandsten vara liggande mellan skiffrar och kalkstenar vid 249 fots djup.

S. om Klittberget àter var sandsten den första bergart man fann. Den låg vid 23 fots djup under jordytan på grå och röd kalksten, antagligen cystidé- och ortocerkalk eller ensamt den senare. Att döma af markens ytförluảllanden kan man antaga, att samma lager temligen orubbadt sträcker sig från sistnämde punkt till Boda kyrkit, och der finna vi i sjelfva kyrkbacken slipsandsten hvilande pả ortocerkalk, bảda skålformigt uppbïjda, nïstan lodrätt stioende.

Vi se således, att flera ornständigheter vilja göra sannolikt, att sandsten, och åtminstone $\mathrm{i}$ de sist nümda fallen slipsandsten, skulle kunna förekomma inuti eller nära de äldre kalkstenarne inom sil. formationen.

Men ännu några ord.

Vid Klittberget går slipsandsten i dagen. Antagligen kan den sandsten, sọm ett stycke söder om berget ligger 23 fot under jordytan, icke vara någon annan. IIä vid Klittberget ïr dock sandstenen tydligen ofverlagrad af leptænakalk. Från samma berg och söderut till Ofvanmyra finnes slipsandsten nära ytan på flera ställen. Söder om Ofvanmyra fortsätter samma höjd med samma längdșluttuing àt $S$., men här, i Sollerga, ligger leptænakalk i dagen. Öster om Solberga, mellan 


\section{4}

Ofvanmyra och Born, brytes ortocerkalk nere $i$ en dal; på höjden vid Born åter är, såsom förut är nämdt, sandsten nästan $\mathrm{i}$ synlig kontakt med leptænakalk. Annnu sydligare brytes ortocerkalk nere vid Gürdsjön.

Allt ifrån Klittberget och Boda i norr till Gärdșjön i söder saknas sålunda, som vi se, alla mellanliggande lager och dermed äfen all antydan om, huru vida IINNaRssoss öfre graptolitskiffer och trinucleusskiffer hafva sin plats mellan leptænakalken och sandstenen eller mellan ortocerkalken och sandstenen. Exemplen från Draggi borrbrunn m. fl. måste derför tills vidare stå nakna och gïlla hrad de kunna såsom bevis för en slipsandsten samtidig med eller nïrstående den äldsta kalkstenen. Huru som helst kunna de dock jcke jïfa de förhållanden, under hvilka sandstenen förekommer synlig jemte yngre silurbildningar på Sollerön och flera andra i början af denma uppsats nämdar ställen, och hvilka $i$ sả måtto fürïndra den hittills uppstälda lagerföljden, att en sandsten måste antagas såsom den, näst efter leptenakalken, yngsta af Dalarnes siluriska bildningar, i stïllet att all sandsten förut blifvit förd till de kambriska.

Den rikt kalkhaltiga sandsten, som förekommer mellan Rättviks kyrka och Draggin, torde utan fara för misstag böra, såsom ock af Tónkqvisx redan blifvit gjordt, niimmast hänföras till leptænakalken. Vid de bảda iakttagna ändpunkterna utmärker sigg demna bergart för sin stora likhet med vanlig röd sandsten och innesluter der små konkretioner af tät, grå eller violett kalksten i form af smá bollar eller tillplattade körtlar. De branta sandstensväggarne i södra sidan af Daggain, V. om bron, lemna bästa tillfillet att se denna bergart.

Slutligen återstår att tala om det slags sandsten, som ö. om Orsasjön och S. om Ore elf utgör underlaget för hela sil. formationen. Från Orsasjön höjer sig marken till en ansenlig höjd, på hvilken flera bjar i Orsa socken ïro beliigna. IÏjjden kallas Digerberget. I sluttningen framträda, såsom redan blifvit sagdt, sil. formationens olika lager, närmare höjden ses ortocerkalken livila mot en fremmande bergart. Till utseendet liknar 
han nágot röd sandsten eller ej. för tät hälleflinta, samt har ofta nog den senares skåliga brott. 1 vissa lager har denna - bergart, som på Geolog. Byrỉn erhaillit namnet Digerbergssandsten, nästan tät struktur, i andra ̈̈ro kornen sá stora, att han blir konglomeratartad. Redan med blotta ögat kan man i de flesta fall urskilja, att beståndsdelarne i den ganska krartsiga grundmassan lufrudsakligen tillhört porfyrer. Verkligt konglomerat har jag sett söder om Skatunge by och måhäinda äfren i östra sluttuingen af Digerberget. Pa füra stället äro de inbäddade stenarne, af röd porfyr, ïnda till hufvudstora. Utom i Digerberget synes samma sandsten vid ذ̇berga och under konglomeratlagret vid Skatunge by; sydligare har jag ingenstiides sett lionom.

Pá biala sidor om Skatunge by samt östligare synes pá flera stälen utmed landsvïgen en bergart, som in mest liknar porfyr, in åter sandsten, ehuru med porfyrartadt utseende. TönXovist har gifvit namnet eurit åt båda varieteterna och skall jag straxt omnämna de iakttagelser rürande dem, som jag gjort pi annat håll.

För att bestämma den relativa áldern mellan Digerbergssandstenen och euritsandstenen äro företeelserna i dessa trakter. icke tillruickliga. Om vi deremot flytta oss lïngre åt $\mathrm{N}$. och taga Elfdalens bergarter i betraktande, skola vi der finna följande serie, rïknadt uppifrån nediat:

Porfyrer af flera slag.

Digervergssandsten med konglomeratlager.

Röd och rōdlrun porfyr.

Euritsandsten.

Euritsandsten, till utseendet temligen lik den omkring Skatunge by, synes i nágra branta klippor vid Dalelfren, $N$. om Elfdals kyrka. IIögre upp frỉn elfven blir bergarten ännu mera porfyrartad och måste anses som verklig porfyr. Färgen är röd till rödbrun och de karakteristiska kristallerna af köttröd och hvit fältspat och något grönsvart glimmermineral, mera sällan kvarts, visa sig spridda i massan. IYykjeberget, N. om Nässjöns 
östra ände - porfyrverket ligger vid sjöns, södra sida - har sådan porfyr vid foten; högre upp förekommer endast Digerbergssandsten och konglomerat i hela den 400 fot tvärbranta vïggen. ${ }^{*}$ ) (Jag kan ej underlåta att, om också-inom parentes, sïrskildt påpeka den betydliga mäktigheten af dessa sandstensoch konglomeratlager samt erinra, att de sannolikt till största delen hafva uppstaitt genom sand och grus, bildadt af krossade porfyrberg.) Norr om IIykjeberget, riitt langt upp i Mora socken, ligger vid gränsen till Elfdalen ett porfyrberg, kalladt Klittberget. Här ser man fortsïttningen upprit af Hykjeberget. I sydvestra sidan ïr nemligen Digerbergssandsten vid foten, i olika lager mörkgrå, rödlett och grågul, så vïl nïstan tät, som ock mindre finkornig till strukturen. Öfver sandstenen är ett konglomeratlager och ännu högre upp först mörk porfyr med nïstan svart grundmassa, derpå rödbrun och sist på höjden röd porfyr.

Att här inlåtí mig pi̊ en nürmare besknifning af de särskilda' porfyrema eller på. frägan om deras sedimentära eller eruptiva uppkomst, hör icke till ämnet för deina uppsats. Ändamalet. har endast varit att genom framstillande af fakta visa, att de olika slagen af sandsten, som finnas i Siljanstrakten, ingalunda böra betraktas sâsom samtida aflagringar, och att hänvisa hvart och ett till dess respektive plats. Den ordningsföljd af Siljanstraktens aflagringar jag på grund af of vanstíende skulle vilja uppställa, blefve således följande:

Leptonakalk,

Sandsten (slipsandsten),

Öfre Graptolit-skiffer, incl. skiffer med inlagrade kalkhvarf (Styggforskalk) eller bollar.

(Brachiopodskiffer?)

Trinucleusskiffer, innefittande, utom den svarta Trinucleusskiffern jemte Gullerảskalk, tillika röd kalkhaltig skiffer med röd kalk.

Chasmopskalk,

Ortocerkalk,

Digerbergssandsten,

Röd porfyr,

Euritsandster.

*) Hōjden enligt en appgift i Vet. Akad. Handl. år 1805, första häftet. 